\title{
Las guerras floridas de Roberto Bolaño: memoria, melan- colia y Pierre Menard
}

Roberto Bolaño's Flower War: Memory, Melancholy, and Pierre Menard

Ignacio López-Calvo

University of California, Merced, California, Estados Unidos

lopezcalvo@msn.com

\section{RESUMEN}

Desde el contexto de la desmitificación de la literatura chilena en el exilio, este ensayo analiza cómo se refleja esta transición desde el activismo político a la decepción y el escepticismo melancólico en la obra del chileno Roberto Bolaño. Tiene también en cuenta el papel de la repetición en la obra de Bolaño como una puesta en práctica de las teorías que presenta Jorge Luis Borges en su cuento «Pierre Menard, autor del Quijote», de la colección Ficciones (1944).

\section{PALABRAS CLAVE}

Roberto Bolaño, guerras floridas, Pierre Menard, memoria, melancolía

\section{ABSTRACT}

Within the context of demythicizing Chilean literature in exile, this essay analyzes the reflection of this move from political activism to a melancholic skepticism and disappointment in Roberto Bolaño's body of work. It also considers the role of repetition in his writing, as an implementation of Jorge Luis Borges's theories presented in his short story «Pierre Menard, autor del Quijote» («Pierre Menard, author of the Quixote»), from the 1944 collection Ficciones.

1 Profesor de Literatura Latinoamericana en la Universidad de California, Merced. Ha publicado los libros Dragons in the Land of the Condor. Tusán Literature and Knowledge in Peru (The University of Arizona Press, 2014), The Affinity of the Eye. Writing Nikkei in Peru (The University of Arizona Press, 2013), Latino Los Angeles in Film and Fiction. The Cultural Production of Social Anxiety (The University of Arizona Press, 2011), entre otros. Ha editado también ocho libros sobre Roberto Bolaño, realismo mágico, orientalismo y otros temas. Es codirector de la revista académica Transmodernity. Journal of Peripheral Cultural Production of the Luso-Hispanic World. 


\section{KEYWORDS}

Roberto Bolaño, flower wars, Pierre Menard, memory, melancholy

En un estudio anterior sobre las novelas chilenas escritas en el exilio tras el golpe de Estado del general Augusto Pinochet de 1973, Written in Exile. Chilean Fiction from 1973-Present (2001), analicé este corpus narrativo desde la doble perspectiva teórica del exilio y la teología de la liberación. El estudio trataba de demostrar la evolución de esta literatura desde un enfoque denunciatorio y testimonial hasta otro desmitificador, que, si bien lamenta el colapso social y denuncia los abusos contra los derechos humanos cometidos por la Junta, problematiza las contradicciones del discurso a veces dogmático de la izquierda. Tanto los testimonios, en su mayor parte escritos inmediatamente después del golpe de Estado, como las narrativas postestimoniales cuestionaban, por medio de la literatura, el discurso oficial. Todavía desde el contexto de la desmitificación de la literatura chilena en el exilio, en este ensayo analizaré cómo se refleja esta transición desde el activismo político a la decepción y el escepticismo melancólico en la obra del chileno Roberto Bolaño. Tendré también en cuenta el papel de la repetición en la obra de Bolaño como una puesta en práctica de las teorías que presenta Jorge Luis Borges en su cuento «Pierre Menard, autor del Quijote», de la colección Ficciones (1944).

El análisis y la contextualización de la obra de Bolaño, en el contexto de la novela desmitificadora en el exilio, abre, a mi juicio, la posibilidad de nuevas interpretaciones. Por ejemplo, el cuento «Últimos atardeceres en la tierra», de la colección Putas asesinas (2001), incluye memorias de la derrota política, la violencia y lo que el protagonista llama las guerras floridas de Latinoamérica, un término que toma prestado del concepto mesoamericano xōchiyaoyōtl, que era una guerra acordada entre comunidades indígenas para capturar prisioneros que pudieran ser sacrificados ritualmente, sobre todo en tiempos de sequía. La elección del término guerra florida sugiere que la violencia es un componente esencial de la vida en la región desde los tiempos precolombinos. Convierte las revoluciones contemporáneas, las dictaduras, las guerras y los feminicidios en una continuación directa de la violencia ritual precolombina; de ahí que aparezca una referencia al sacrificio humano azteca, aparentemente fuera de contexto, en una conversación entre Reiter y una joven en su novela 2666: «una piedra semejante a la mesa de un quirófano, en donde los sacerdotes o médicos aztecas extendían a sus víctimas antes de arrancarles el corazón» (Bolaño, 2008, p. 872). La breve aventura de Bolaño en el Chile inmediatamente posterior al golpe de Estado (llegó justo antes del golpe y fue encarcelado ocho días) se describe livianamente en «Últimos 
atardeceres en la tierra» como un mero ritual, sin connotaciones épicas o de heroísmo. Por el contrario, los recuerdos del protagonista autobiográfico, B, se mezclan con los de su lectura de las obras de un poeta menor francés, su interacción con prostitutas en un burdel mexicano y la descripción del alivio que sintió una vez que su avión aterrizó en Acapulco. Si bien mantiene misteriosamente que ciertas cosas no se pueden contar, el tono menor, antiheroico de los eventos se enfatiza con la reacción de su padre: cuando B regresa de Chile en 1974 y le confiesa a su padre que casi lo mataron, este simplemente le pregunta: «¿Cuántas veces?», antes de soltar una carcajada. No solo es evidente que el padre del protagonista no se toma en serio su encarcelamiento ni el haber estado cerca de morir, sino que las circunstancias en que $B$ recuerda estas experiencias sugieren que tampoco él se las toma muy en serio. De hecho, el mismo Bolaño ha hablado en varias entrevistas de su experiencia carcelaria con un tono desenfadado: «Estuve detenido por ocho días, aunque hace poco en Italia me preguntaron: ¿cómo fue su experiencia de pasar medio año en prisión? Se debe a un error de una edición alemana, donde pusieron que había estado seis meses en la cárcel... Es el típico tango latinoamericano. En el primer libro mío publicado en alemán pusieron que había estado un mes; en el segundo — viendo que el primero no había vendido mucholo elevaron a tres meses; en el tercero subí a cuatro y en el cuarto fueron cinco meses. Así como va el asunto, debería estar prisionero hasta el día de hoy» (Capital Online, 2009). Bolaño menciona las guerras floridas latinoamericanas en varios otros textos, incluyendo su ensayo «El pasillo sin salida aparente» y su discurso de aceptación del Premio Rómulo Gallegos. En este discurso, aclara: «Esto que quede claro, pues como los veteranos del Lepanto de Cervantes y como los veteranos de las guerras floridas de Latinoamérica, mi única riqueza es mi honra» (Bolaño, 2004, p. 39). Más adelante, tras compararlo con el discurso de las armas y las letras de Cervantes, enfatiza la importancia de estas guerras floridas como fuente de inspiración en su obra:

todo lo que he escrito es una carta de amor o de despedida a mi propia generación, los que nacimos en la década del cincuenta y los que escogimos en un momento dado el ejercicio de la milicia, en este caso sería más correcto decir la militancia, y entregamos lo poco que teníamos, lo mucho que teníamos, que era nuestra juventud, a una causa que creímos la más generosa de las causas del mundo y que en cierta forma lo era, pero que en la realidad no lo era. De más está decir que luchamos a brazo partido, pero tuvimos jefes corruptos, líderes cobardes, un aparato de propaganda que era peor que una leprosería, luchamos por partidos que de haber vencido nos habrían enviado de inmediato a un campo de trabajos forzados, luchamos y 
pusimos toda nuestra generosidad en un ideal que hacía más de cincuenta años que estaba muerto, y algunos lo sabíamos, y cómo no lo íbamos a saber si habíamos leído a Trotski o éramos trotskistas, pero igual lo hicimos, porque fuimos estúpidos y generosos, como son los jóvenes, que todo lo entregan y no piden nada a cambio, y ahora de esos jóvenes ya no queda nada, los que no murieron en Bolivia murieron en Argentina o en Perú, y los que sobrevivieron se fueron a morir a Chile o a México, y a los que no mataron allí los mataron después en Nicaragua, en Colombia, en El Salvador. Toda Latinoamérica está sembrada con los huesos de estos jóvenes olvidados (Bolaño, 2004, pp. 37-38).

La sombra de estas guerras floridas abarca gran parte de la obra de Bolaño, en la que encontramos un triste recuerdo de la pérdida fútil de juventud y de vida, así como una descripción desmitificadora y antiheroica de la vida en el exilio, a pesar del hecho de que, como explica Wilfrido Corral (2011, p. 197), Bolaño no «se pensó a sí mismo como memorialista del exilio o de los males de la ausencia». Así pues, el cuento «El Ojo Silva», incluido también en Putas asesinas, se abre con el intento del protagonista de escapar a la violencia, aun cuando, en palabras del narrador, su generación (es decir, los que tenían unos veinte años cuando falleció Salvador Allende) nunca logra escapar del todo a la verdadera violencia. El segundo párrafo aclara que su experiencia es una sinécdoque de las vicisitudes de su generación: «El caso del Ojo es paradigmático y ejemplar» (Bolaño, 2010, p. 215). En consonancia con la novela desmitificadora chilena en el exilio, ya aparece una dura crítica del comportamiento de los exiliados chilenos en el cuarto párrafo: «No era como la mayoría de los chilenos que por entonces vivían en el D. F.: no se vanagloriaba de haber participado en una resistencia más fantasmal que real, no frecuentaba los círculos de exiliados» (Bolaño, 2010, p. 215). Como en la novela del también chileno José Donoso El jardín de al lado² (1981), en la que el protagonista exiliado exagera su experiencia carcelaria para ganar capital simbólico como escritor chileno en España, en «El Ojo Silva» se nos dice que la mayoría de los exiliados chilenos miente sobre su participación en la resistencia contra la junta militar de Pinochet. La crítica explícita continúa en las primeras páginas de la historia: nos enteramos de que chismean sobre la homosexualidad de El Ojo Silva, porque «alimentaba la vida más bien aburrida de los exiliados, gente de izquierdas que pensaba, al menos de cintura para abajo, exactamente igual que la gente de derechas que en aquel tiempo se enseñoreaba de Chile» (Bolaño, 2010, p. 216). Y no solo es la vida de

2 Bolaño analiza El jardín de al lado en su ensayo «El misterio transparente de José Donoso», incluido en su colección Entre paréntesis. 
los exiliados más aburrida que heroica, sino que también los acusa de ser homófobos: El Ojo le confiesa al narrador que, durante años, se sintió obligado a esconder sus preferencias sexuales por miedo a sufrir el prejuicio de los otros izquierdistas. La conversación entre El Ojo y el narrador llega a un punto en que atacan vehementemente a la izquierda chilena y el narrador extiende su crítica a los exiliados latinoamericanos: «yo brindé por los luchadores chilenos errantes, una fracción numerosa de los luchadores latinoamericanos errantes, entelequia compuesta de huérfanos que, como su nombre indica, erraban por el ancho mundo ofreciendo sus servicios al mejor postor, que casi siempre, por lo demás, era el peor» (Bolaño, 2010, p. 217). En realidad, El Ojo, el único ejemplo positivo entre los exiliados chilenos, se usa como punto de contraste para exponer la falta de integridad de los otros exiliados chilenos.

Aunque el narrador se da cuenta de que El Ojo nunca aprobaría las generalizaciones que está haciendo, no llega realmente a rectificar su condena de las exageraciones, mentiras y corrupción moral de los exiliados chilenos, una crítica que, dicho sea de paso, a veces parece un tanto desconectada del resto del argumento. El Ojo acaba salvando a unos jóvenes de la castración y la prostitución en India y, según la voz narrativa, esto no debería sorprender al lector: «la violencia de la que no podemos escapar. El destino de los latinoamericanos nacidos en la década de los cincuenta» (Bolaño, 2010, p. 225). Hacia el final del cuento, después de contarle al narrador que los niños que salvó acabaron muriendo por una enfermedad en India, El Ojo vuelve a su hotel y llora por estos niños, por otros niños castrados a los que nunca conoció, por su propia juventud «por todos los jóvenes que ya no eran jóvenes y por los jóvenes que murieron jóvenes, por los que lucharon por Salvador Allende y por los que tuvieron miedo de luchar por Salvador Allende» (Bolaño, 2010, p. 228). El cuento, por tanto, acaba con la nostalgia y la decepción por el fin del sueño utópico, y con el reconocimiento de lo inescapable que es la violencia que sigue a los latinoamericanos nacidos en los años cincuenta, sin importar adónde vayan. En definitiva, las aventuras de El Ojo en India no son más que una desesperada continuación de la misma búsqueda de justicia por la que su generación inconformista perdió su juventud. Un sentimiento omnipresente de melancolía y fracaso ontológico parece abrumar a El Ojo, el narrador y el propio autor implícito. No obstante, como Belano en la novela Amuleto (1999), que rescata valientemente a un joven poeta homosexual de su proxeneta, aquí El Ojo es lo suficientemente intrépido como para pelear por otra causa. Es decir que, a pesar de su profunda decepción, no ha tirado la toalla en su lucha por la justicia social $y$, al menos por un tiempo, consigue ganar una batalla menor en India. Como se puede observar, 
algunos de los personajes de Bolaño no se rinden, como parece sugerir Jean Franco en su ensayo "Questions for Bolaño»; a pesar de su aparente resignación, continúa luchando, aun si ahora se trata de una lucha en batallas menores y locales. De hecho, Bolaño mismo se niega a considerar su literatura pesimista: «[Mis textos] Son bastante optimistas, porque mis personajes no se suicidan, aguantan. Al menos no todos se suicidan» (Braithwaite, 2008, p. 117).

Por el mismo camino, el cuento «Días de 1978», incluido en Putas asesinas, abre con la llegada del protagonista aparentemente autobiográfico, $B$, a una fiesta organizada por los exiliados chilenos. Pronto nos enteramos de que no le caen bien los exiliados chilenos en Barcelona, a pesar de ser él mismo uno de ellos. Durante la fiesta, tiene una violenta discusión con otro izquierdista chileno (un miembro del Movimiento de Izquierda Revolucionaria, MIR), quien, hacia el final de la historia, se suicida en Francia. El narrador omnisciente describe, en el presente, la decepción de B con la izquierda chilena: «La violencia de $U$, sin embargo, lo lleva a sacar amargas conclusiones, pues $U$ ha militado y tal vez aún milita en uno de los partidos de izquierda que $B$ contemplaba, en aquella época, con más simpatía. La realidad, una vez más, le ha demostrado que la demagogia, el dogmatismo y la ignorancia no son patrimonio de ningún grupo concreto» (Bolaño, 2010, p. 266). El suicidio de $U$ sume al protagonista en un sentimiento de culpa y tristeza. Al final, este contacto con otros exiliados chilenos no hace sino aumentar su melancolía y decepción con la izquierda chilena a la que perteneció unos años antes.

Pero la crítica de Bolaño va más allá del mundo de los exiliados. Otros cuentos exponen cómo algunos izquierdistas que se quedaron en Chile durante y después del golpe de Estado acabaron traicionando a su causa. Ese es el caso de dos soldados en «Detectives», incluido en la colección Llamadas telefónicas (1997), que sirven a la dictadura, aun cuando afirman haber sido encarcelados tres días inmediatamente después del golpe por ser izquierdistas. En dos pasajes diferentes, ambos muestran su sentimiento de culpabilidad, recordando a Belano (de nuevo el álter ego de Bolaño), que, en el presente del cuento, continúan siendo secretamente izquierdistas. A pesar de su arrepentimiento por haber matado a tantos jóvenes valientes en 1973, los dos soldados admiten sin reparos que violaron a prostitutas cada noche y que habrían torturado a prisioneros si se lo hubieran ordenado. Uno de ellos incluso se plantea asesinar a Arturo Belano, su antiguo compañero de clase. La historia es, por supuesto, un recuento del breve encarcelamiento de Bolaño en Chile, antes de que lo salvaran sus antiguos compañeros de clase que vigilaban a los prisioneros en la cárcel. En la ficción, los eventos se recuerdan años después por medio 
de un diálogo entre dos personajes que exponen, una vez más, las fallas de la izquierda chilena, incluyendo a sus más jóvenes militantes (los dos soldados tenían 20 años cuando ocurrió el golpe). De hecho, este cuento presenta el caso más extremo: el de militantes que fueron encarcelados, pero luego traicionaron su causa original, hasta el punto de matar a sus antiguos camaradas y violar diariamente a prostitutas encarceladas. La solemnidad de la condena queda enfatizada por el hecho de que se trata de datos autobiográficos.

Bolaño vuelve a mencionar su encarcelamiento en la novela La pista de hielo (1993), el último capítulo de La literatura nazi en América, su cuento «Compañeros de celda», también incluido en Llamadas telefónicas, y «Carnet de baile», de Putas asesinas. En este último cuento, el narrador en primera persona explica que en agosto de 1973 volvió a Chile después de un largo viaje por tierra y mar, con el objeto de participar en la construcción del socialismo. Como en los otros textos, en vez de agregar matices épicos o heroicos a sus acciones, el narrador confiesa que el día del golpe se ofreció de voluntario en una célula de un barrio, pero acabó vigilando una calle totalmente vacía y olvidando la contraseña que le habían dado; en sus propias palabras: «El once de septiembre fue para mí, además de un espectáculo sangriento, un espectáculo humorístico» (Bolaño, 2010, p. 402). Después Bolaño mezcla, con un tono despreocupado, recuerdos de su activismo político en Chile con los de lecturas recientes e incluso con un comentario sobre los libros que tenía el trabajador comunista que dirigía la célula del barrio. Un día, viajando en autobús de Los Ángeles, capital de la provincia de Bío-Bío, a Concepción, lo arrestan y encarcelan bajo sospecha de ser un terrorista extranjero. El narrador recuerda que, aunque no fue torturado, no le dieron comida ni manta, y sobrevivió solo gracias a la caridad de otros presos. Esta vez, su crítica a los chilenos (muy parecida a la de Poli Délano en Casi los ingleses de América) llega después de explicar que lo salvaron dos antiguos compañeros de la escuela secundaria y su amigo Fernando Fernández, «cuya sangre fría era sin duda equiparable a la imagen ideal del inglés que los chilenos desesperada y vanamente intentaron tener de sí mismos» (p. 403). En contraste con las historias anteriores, sin embargo, los exiliados chilenos que se retratan aquí no son gente aburrida ni vividores, sino mujeres brutalmente torturadas que podrían haber inspirado el interés de Bolaño en la tortura de mujeres en Ciudad Juárez, ficcionalizada en 2666: «En México me contaron la historia de una muchacha del MIR a la que torturaron introduciéndole ratas vivas por la vagina. Esta muchacha pudo exiliarse y llegó al D. F. Vivía allí, pero cada día estaba más triste y un día murió de tanta tristeza» (Bolaño, 2008, p. 403). Según el narrador, esta historia parece ubicua: le ocurrió también 
a una chilena exiliada en París y a otra en Estocolmo, lo que le hace preguntarse si quizá se trataría de la misma mujer en los tres casos. Después, menciona las tribulaciones de tres hermanos argentinos que murieron en tres revoluciones diferentes, tras traicionarse entre ellos. En consonancia con la tendencia de Bolaño a la ironía y el sarcasmo, mezcla estas historias terriblemente tristes con el recuerdo de apariciones de Hitler y Neruda en el pasillo de su casa, solo para acabar cerrando la historia con la tristeza de recordar a todos los jóvenes latinoamericanos que perdieron su vida por un sueño utópico: «Todos los que creyeron en el paraíso latinoamericano y murieron en el infierno latinoamericano. Pienso en esas obras que acaso permitan a la izquierda salir del foso de la vergüenza y la inoperancia» (Bolaño, 2010, p. 406). Las últimas palabras de la cita sugieren la decepción del protagonista (y probablemente también de su autor) con la izquierda latinoamericana y deja el mismo resabio de tristeza y melancolía que caracteriza otros textos. Quizás todavía más trágico para Bolaño, el fracaso de la revolución lleva consigo la inevitable caída de la vanguardia literaria. Como señala Ignacio Echevarría (2013, p. 197): «El proyecto revolucionario, pues, era inseparable, para Bolaño, del proyecto artístico. Y el fracaso de uno conlleva el del otro». Paradójicamente, en otros textos, como el ensayo «Exilios», Bolaño recuerda nostálgicamente la emoción de los cinco meses que pasó en Chile inmediatamente después del golpe de Estado. Se mezclan, por tanto, recuerdos de sus aventuras y de la alegría de vivir con la terrible decepción por la futilidad de la resistencia. Aun si el idealismo juvenil se ha esfumado, varios de los personajes de Bolaño continúan siendo valientes e incorformistas, luchando pequeñas batallas hasta el final.

Con respecto a sus novelas, en Los detectives salvajes (1998) la autocrítica se vuelve aún más dura. Como si Bolaño estuviera tratando de poner en práctica las teorías que propone Borges en el cuento «Pierre Menard, autor del Quijote» sobre el valor de la reescritura de los mismos párrafos en diferentes contextos y desde puntos de vista narrativos diferentes, se nos dice de nuevo que Arturo Belano regresó a su patria «a hacer la revolución» (Bolaño, 1998, p. 195), después de un largo y peligroso viaje, pero acabó vigilando absurdamente una calle vacía el 11 de setiembre de 1973. Si las afirmaciones irónicas de Borges son ciertas, la reescritura literal de párrafos sirve un propósito específico: los párrafos son prácticamente idénticos palabra por palabra, pero diferentes; no son una copia o una transcripción mecánica. Según el narrador del cuento de Borges «Pierre Menard, autor del Quijote», el texto escrito por el simbolista francés en el título es infinitamente más rico ambiguo que el de Cervantes: el nuevo contexto contemporáneo y la perspectiva narrativa han enriquecido 
el texto con connotaciones que estaban ausentes del texto original. Lo mismo ocurre, por tanto, con los nuevos párrafos casi idénticos que Bolaño reescribe: más que autoplagio, estas variaciones no jerárquicas de la misma historia deben ganar en valor connotativo según la historia se expande rizomáticamente en su obra, sin que se tenga que llegar a una conclusión. Es importante recordar que Bolaño concebía su obra como una unidad coherente y que declaró, en varias entrevistas, que todos sus libros están relacionados entre sí y que, por ello, la mejor manera de entenderlos era leerlos todos: «concibo, de una manera muy humilde, la totalidad de mi obra en prosa e incluso alguna parte de mi poesía como un todo. Un todo no solo estilístico, sino también un todo argumental: los personajes están dialogando continuamente entre ellos y están apareciendo y desapareciendo» (Braithwaite, 2008, p. 112).

Quizá, al igual que Menard reescribe la obra de Cervantes y Cervantes reescribe paródicamente la tradición literaria española en su obra maestra, Bolaño podría estar reescribiendo la literatura denunciatoria y liberacionista chilena en el exilio, con la que, como es bien sabido, era sumamente crítico: «De la literatura chilena en el exilio yo diría, en primer término, que no es literatura, y en segundo que tampoco es en el exilio. En rigor, no hay una literatura chilena en el exilio, y la que hay a mí me parece bastante mala» (Paz y Faverón, 2008, p. 60). En efecto, en su ensayo «Sobre la literatura, el premio nacional de literatura y los raros consuelos del oficio», Bolaño fue particularmente duro con Isabel Allende, Antonio Skármeta y Volodia Teitelboim, quienes quedan más tarde contextualizados en un marco poco alentador de la literatura chilena en general: «La literatura chilena, tan prestigiosa en Chile, no tiene más de cinco nombres válidos, eso hay que recordarlo como ejercicio crítico y autocrítico» (Bolaño, 2004, p. 104). Desde la perspectiva de este desdeño por la literatura testimonial y liberacionista en el exilio, su propia experiencia como militante se acaba describiendo en Los detectives salvajes como el tradicional rito de paso del machismo latinoamericano: «el viaje iniciático de todos los pobres muchachos latinoamericanos, recorrer este continente absurdo» (Bolaño, 1998, p. 195).

Tras su regreso a México, Belano empezó a salir con amigos más jóvenes como Ulises Lima y a mofarse de sus antiguos amigos, a la vez que mantuvo su ego de macho a salvo, una referencia al machismo que desgraciadamente se pierde en la traducción que se publicó en inglés: «Arturito había cumplido y su conciencia, su terrible conciencia de machito latinoamericano, en teoría no tenía nada que reprocharse» (Bolaño, 1998, p. 195) (en inglés: «Arturito had done his duty, and his conscience, the terrible conscience of a young Latin American male, had nothing with 
which to reproach itself» [p. 178]). Además, siente que durante su breve encarcelamiento «se comportó como un hombre» (Bolaño, 1998, p. 196). Las acciones del protagonista, por tanto, se interpretan como una especie de pose de macho, algo que se corrobora en una entrevista con Daniel Swinburn (2008, p. 74), en la que Bolaño responde: «En el caso de mi generación, bueno, nuestro valor fue tan grande como nuestra inocencia o estupidez. Digamos que, en esa épica, lo que contaba era el gesto. Mediante gestos uno construía su novela de aprendizaje, algo que bien mirado es bastante tonto y que a la postre, si las cosas hubieran sido diferentes, nos habría convertido en víctimas» [la cursiva es mía]. Aún más sorprendentemente, en otra entrevista, está vez con Ima Sanchís, su participación en actividades revolucionarias se presenta como una simple continuación de su naturaleza violenta. A la pregunta de si era un chico destructivo, responde: «Sí, y me exhibía como malo, pero me da vergüenza contarlo. No robe ni violé, pero fui un joven violento. A los 19 años decidí que quería hacer la revolución» (Sanchíz, 2008, p. 80).

Para continuar con la naturaleza paródica de gran parte de Los detectives salvajes, aunque su nuevo amigo Ulises Lima afirma que son revolucionarios que fueron encarcelados, se les describe con frecuencia a él y a Belano como narcotraficantes, más que como exiliados o heroicos jóvenes que luchan por la libertad. En cualquier caso, a lo largo del libro, los amigos de Belano recuerdan cómo contaba «historias de amigos que habían muerto en las guerrillas de Latinoamérica» (Bolaño, 1998, p. 411). La futilidad de estas muertes sigue siendo un sentimiento sobrecogedor, pero al mezclarlo con el machismo, el esnobismo y el narcotráfico, el potencial testimonial o denunciatorio de estos párrafos queda diluido. En otras palabras, Bolaño socaba su propia denuncia literaria e incluso su traumática experiencia vital para mofarse indirectamente de los valores de la izquierda chilena ( $y$, por extensión, de la latinoamericana), así como de la literatura chilena escrita en el exilio y sobre el exilio.

Igualmente, en el capítulo 19 el sarcasmo del narrador, al mencionar los comentarios hechos por un grupo de exiliados chilenos que se reúnen en un café parisino a conmemorar el décimo aniversario del golpe de Estado el 11 de setiembre, acaba con la solemnidad del momento: «Estábamos un grupo de chilenos masoquistas reunidos para recordar la infausta fecha... De repente alguien, no sé quién, se puso a hablar del mal, del crimen que nos había cubierto con su enorme ala negra. ¡Hágame el favor! ¡Su enorme ala negra! ¡Los chilenos está visto que no aprendemos nunca!» (Bolaño, 1998, pp. 396-397). Pero, de repente, lo que parece una simple mofa de una mala elección de lenguaje lírico acaba convirtiéndose en una conversación sobre el mal en general (un tema clave en la obra de Bolaño), 
que puede proveer pistas para entender una de sus obras maestras, 2666: «Belano, le dije, el meollo de la cuestión es saber si el mal (o el delito o el crimen o como usted quiera llamarle) es casual o causal. Si es causal, podemos luchar contra él, es difícil de derrotar pero hay una posibilidad, más o menos como dos boxeadores del mismo peso. Si es casual, por el contrario, estamos jodidos. Que Dios, si existe, nos pille confesados. Y a eso se resume todo» (Bolaño, 1998, p. 397). En cualquier caso, la imagen de los exiliados e inmigrantes latinoamericanos en España sigue siendo bastante negativa, como se observa en la descripción de las colas que forman para hablar en teléfonos públicos estropeados: «En esas colas se juntaba lo mejor y lo peor de Latinoamérica, los antiguos militantes y los violadores, los expresos políticos y los despiadados comerciantes de bisutería» (Bolaño, 1998, p. 412). Estos párrafos agudizan la desmitificación de la lucha social izquierdista en Latinoamérica y de la experiencia del exilio que aparece en la obra de Bolaño. Como si estuviera intentando asegurarse de que el lector recibe su mensaje, y de nuevo usando los trucos narrativos de Pierre Menard, el mismo rito de paso del viaje a Chile reaparece en su novela Amuleto (1999), en la que, coincidiendo con la novela de Poli Délano En este lugar sagrado, la protagonista y narradora en primera persona se esconde en un cuarto de baño público de la universidad, mientras que tienen lugar importantes cambios sociales fuera del edificio. Esta vez, es Auxilio Lacouture, la narradora uruguaya que se autobautiza como «madre de la poesía joven de México» (Bolaño, 1999, p. 38), la que nos informa sobre la experiencia de Arturo Belano en Chile y de su regreso a México. Describe lo orgulloso que estaba de la victoria de Salvador Allende en las elecciones presidenciales chilenas, su deseo de participar en el revolución y su largo y peligroso viaje a Chile: «el viaje iniciático de todos los pobres muchachos latinoamericanos, recorrer este continente absurdo que entendemos mal o que de plano no entendemos» (Bolaño, 1999, p. 63). Después, el viaje se describe de nuevo de manera peyorativa en el contexto del machismo latinoamericano: «Cuando Arturo regresó a México, en enero de 1974, ya era otro. Allende había caído y él había cumplido con su deber, eso me lo contó su hermana, Arturito había cumplido y su conciencia, su terrible conciencia de machito latinoamericano, en teoría no tenía nada que reprocharse» (Bolaño, 1999, p. 66). Nos enteramos de que cuando regresó a México, Belano había cambiado tanto que sus amigos ya no lo reconocían. Comienza a mofarse de ellos, a despreciarlos y a juntarse con amigos más jóvenes con los que vende marihuana y otras drogas. Lacouture también recuerda la participación de la familia de Belano en una manifestación en la Ciudad de México contra el golpe de Pinochet, en un momento en que todavía no sabían del paradero de Belano. 
Llega incluso a considerar la posibilidad de que el joven haya encontrado su «destino latinoamericano»: «tal vez Arturito ya esté muerto, pensé, tal vez este valle solitario sea la figuración del valle de la muerte, porque la muerte es el báculo de Latinoamérica y Latinoamérica no puede caminar sin su báculo» (Bolaño, 1999, pp. 67-68).

Una vez que regresa a México, los amigos de Belano esperan que describa el horror del golpe en Chile, pero se mantiene callado y aparentemente indolente, mientras que su comportamiento se sigue describiendo en términos de machismo latinoamericano: «para ellos Arturito ahora estaba instalado en la categoría de aquellos que han visto la muerte de cerca, en la subcategoría de los tipos duros, y eso, en la jerarquía de los machitos desesperados de Latinoamérica, era un diploma, un jardín de medallas indesdeñable» (Bolaño, 1999, p. 71). La naturaleza autobiográfica de este pasaje queda corroborada en una entrevista con Ima Sanchís, en la que Bolaño reconoce que al regresar a México adoptó una nueva actitud: «Me dediqué a escribir con mi aura de veterano de guerra» (Sanchís, 2008, p. 81). Por alguna razón desconocida, en Amuleto, Lacouture, quien sabe que Belano pasó ocho días en la cárcel comportándose con valentía pero que no fue torturado, decide exagerar algunas de sus hazañas e inventar otras, siempre rodeándolo de un aura heroico: «orné su retorno con colores tomados de la paleta de la poesía épica» (Bolaño, 1999, p. 71). Aunque la mayoría de los amigos de Belano no se creen del todo las historias de Lacouture, uno de ellos, Ernesto San Epifanio, está convencido de que su intrépido amigo chileno puede salvarlo de un hombre que lo obliga a prostituirse. Contra todo pronóstico, Belano accede a ayudarle e incluso consigue intimidar al proxeneta, con lo que salva no solo a San Epifanio, sino también a otro joven poeta homosexual, Juan de Dios Montes, que estaba a punto de morir. De acuerdo con Lacouture, con ello Belano había sido definitivamente promovido al rango de veterano de las guerras floridas latinoamericanas. La novela acaba con la imagen de Lacouture escuchando la voz de un ángel que conoce el paradero de la juventud del continente. La autoproclamada madre de la poesía mexicana ahora suena como la melancólica madre de toda una generación de jóvenes latinoamericanos ingenuos que habían dado su vida con la esperanza de crear un mundo mejor. Las últimas líneas de la novela explican su título: «Y aunque el canto que escuché hablaba de la guerra, de las hazañas heroicas de una generación entera de jóvenes latinoamericanos sacrificados, yo supe que por encima de todo hablaba del valor y de los espejos, deseo y del placer. Y ese canto es nuestro amuleto» (Bolaño, 1999, p. 154).

A pesar del sentimiento de decepción general, entonces, el lector puede percibir la simpatía que tiene el lector implícito por estos jóvenes 
latinoamericanos y por su cosmovisión. Bolaño, que se consideraba a sí mismo un sobreviviente de esta lucha, expresó en varias entrevistas su admiración por esta actitud. No obstante, el análisis que hace Jean Franco de la perspectiva que tiene Bolaño de las luchas izquierdistas latinoamericanas es más negativo: «Destitute of belief after the disasters of the twentieth century, Bolaño's characters have little left to amuse themselves besides occasional friendships and trivial pursuits including literature. Survivors of a great disaster, they are left chasing an always elusive real» (Franco, 2009, p. 208). En efecto, en Amuleto Belano, el desengañado veterano de las guerras floridas latinoamericanas, actúa con la mayor desconsideración por su propia vida, como si ya no tuviera nada que perder, más que la literatura y sus fugaces amistades. Si bien la gran narrativa del socialismo se ha desmoronado y ha dejado de ser la llave a un mundo nuevo, la nueva Latinoamérica neoliberal tampoco resulta un lugar acogedor para los personajes de Bolaño. Al parecer, todo lo que queda es el ennui de Baudelaire, como se expresa en el epígrafe de 2666: «Un oasis de horror en medio de un desierto de aburrimiento». Sin embargo, Belano, como Mauricio, El Ojo Silva, sigue teniendo el coraje para luchar ganar una batalla menor, esta vez en la ciudad de México.

La anécdota que han contado varios escritores latinoamericanos sobre cómo Bolaño contó el mismo chiste con variaciones diferentes en un congreso en Sevilla podría ser una de las claves para comprender cómo entendía la literatura: la misma historia puede ofrecer mensajes diferentes cuando se cuenta varias veces con diferentes estilos, usando diferentes tipos de discurso y diferentes contextos, y los lectores deben convertirse en detectives salvajes en busca de significados. Como se ha observado, a lo largo de su obra Bolaño homenajea melancólicamente una y otra vez a los esperanzados jóvenes latinoamericanos que arriesgaron o perdieron sus vidas con la esperanza de crear un mundo mejor. Este homenaje, no obstante, se mezcla con el resentimiento por aquellos que, tanto en Chile como en el exilio, traicionaron sus ideales.

Varios críticos han notado lo recurrente que es la melancolía en la obra de Bolaño. Carlos Franz, por ejemplo, se pregunta: «Casi todos los libros de $B$ son ferozmente melancólicos (ferocidad y melancolía, a un tiempo). Tanto que bordean peligrosamente el sentimentalismo — todo lo bordea peligrosamente, B-, y luego entran de lleno en él. Y luego "se ahogan" en esa melancolía y luego salen más bien fortalecidos, casi invulnerables. ¿Cómo diablos lo hacía B?» (Franz, 2008, p. 103). Franz señala también que la melancolía de sus personajes se mezcla con ira y resentimiento, lo que considera parte de la estética nihilista del autor. De hecho, las descripciones autodenigrantes que hace Bolaño de su álter ego Arturo Belano 
confirman su gran decepción con la izquierda latinoamericana y con las guerras floridas que perdieron una y otra vez. De alguna manera, invierte el famoso "Discurso de las armas y las letras» de Cervantes, para quien el capital simbólico de haber sido un soldado que luchó por el Imperio español era superior a ningún capital que pudiera tener como escrito. Bolaño menciona este pasaje de Cervantes en el «Discurso de Caracas», pero lo invierte: arriesgar su vida de joven luchando por la construcción del socialismo en su patria se ve como una empresa un tanto absurda; solo escribir sobre ello, es decir, las letras, su actividad literaria, lo salvan, proporcionándole la «respetabilidad» que necesitaba. Como se mencionó, independientemente de lo inútiles que puedan haber sido estos esfuerzos, Bolaño nunca deja de admirar el valor de estos jóvenes latinoamericanos. Esto es evidente en el ensayo "Acerca de Los detectives salvajes», donde afirma: «la novela intenta reflejar una cierta derrota generacional y también la felicidad de una generación, felicidad que en ocasiones fue el valor y los límites del valor» (Bolaño, 2004, p. 327). El autor, sin embargo, se cuida de no presentarse a sí mismo como la voz de los chilenos. Por ello, como si Bolaño estuviera hablando sobre sí mismo, en Los sinsabores del verdadero policía leemos que Amalfitano solo está suponiendo cosas sobre los chilenos porque llevaba mucho tiempo sin asociarse con ellos. En cualquier caso, a juzgar por su reputación como el escritor más influyente de su generación, Bolaño convirtió este fracaso como militante en un gran éxito como hombre de letras. $Y$ en este esfuerzo final para ganar capital cultural como escritor, las técnicas recomendadas por Pierre Menard fueron una útil herramienta de comunicación, crítica y parodia. Bolaño retoca una y otra vez las mismas historias como si estuviera poniendo en práctica estas teorías o bien los 99 ejercicios de estilo de Raymond Queneau, con frecuencia homenajeando a los latinoamericanos de su generación que perdieron su juventud en una lucha yerma esperando conseguir el ideal de la liberación. 


\section{REFERENCIAS BIBLIOGRÁFICAS}

Bolaño, R. (2008). 2666. Barcelona: Anagrama.

(2011). About The Savage Detectives. En Echevarría, I. (Ed.). Between Parenthesis. Essays, Articles, and Speeches, 1998-2003 (pp. 353-353). Nueva York: New Directions.

(2004). Acerca de Los detectives salvajes. En Echevarría, I. (Ed.). Entre paréntesis. Ensayos, artículos y discursos (1998-2003) (pp. 326327). Barcelona: Anagrama.

(1999). Amuleto. Barcelona: Anagrama.

Caracas Address. En Echevarría, I. (Ed.), Between Parenthesis. Essays, Articles, and Speeches, 1998-2003 (pp. 28-37). Nueva York: New Directions.

(2010). Carnet de baile. En Cuentos. Llamadas telefónicas. Putas asesinas. El gaucho insufrible (pp. 398-406). Barcelona: Anagrama.

New Directions.

(2010). Cell Mates. The Return (pp. 57-68). Nueva York:

(2004) Chilean Literature. En Echevarría, I. (Ed.). Between Parenthesis. Essays, Articles, and Speeches, 1998-2003 (pp. 124-126). Nueva York: New Directions.

(2010). Compañeros de celda. Cuentos. Llamadas telefónicas. Putas asesinas. El gaucho insufrible (pp. 141-151). Barcelona: Anagrama.

(2011). The Corridor with No Apparent Way Out. En Echevarría, I. (Ed.). Between Parenthesis. Essays, Articles, and Speeches, 1998-2003 (pp. 75-83). Nueva York: New Directions.

Nueva York: New Directions.

(2006). Dance Card. Last Evenings on Earth (p. 210).

(2006). Days of 1978. Last Evenings on Earth (pp. 158171). Nueva York: New Directions.

(2010). Detectives. Cuentos. Llamadas telefónicas. Putas asesinas. El gaucho insufrible (pp. 118-37). Barcelona: Anagrama.

New Directions.

(2010). Detectives. The Return (pp. 35-56). Nueva York:

(1998). Los detectives salvajes. Nueva York: Vintage

Español.

(2010). Días de 1978. Cuentos. Llamadas telefónicas. Putas asesinas. El gaucho insufrible (pp. 265-278). Barcelona: Anagrama. 
(2004). Discurso de Caracas. Acerca de Los detectives salvajes. En Echevarría, I. (Ed.). Entre paréntesis. Ensayos, artículos y discursos (1998-2003) (pp. 31-39). Barcelona: Anagrama.

(2004). Distant Star. Nueva York: New Directions.

(1996). Estrella distante. Barcelona: Anagrama.

(2011). Exiles. En Echevarría, I. (Ed.). Between Parenthesis. Essays, Articles, and Speeches, 1998-2003. Nueva York: New Directions.

(2004). Exilios. Acerca de Los detectives salvajes. En Echevarría, I. (Ed.). Entre paréntesis. Ensayos, artículos y discursos (19982003) (pp. 49-58). Barcelona: Anagrama.

(2006). Last evenings on Earth. Last Evenings on Earth (pp. 131-57). Nueva York: New Directions.

(2004). La literatura chilena. En Echevarría, I. (Ed.). Entre paréntesis. Ensayos, artículos y discursos (1998-2003) (pp. 115-117). Barcelona: Anagrama.

Barral.

(2005). La literatura nazi en América. Barcelona: Seix

(2006). Mauricio («The Eye») Silva. Last Evenings on Earth (pp. 106-120). Nueva York: New Directions.

(2004). El misterio transparente de José Donoso. En Echevarría, I. (Ed.). Entre paréntesis. Ensayos, artículos y discursos (19982003) (pp. 99-101). Barcelona: Anagrama.

(2010). El Ojo Silva. Cuentos. Llamadas telefónicas. Putas asesinas. El gaucho insufrible (pp. 205-228). Barcelona: Anagrama.

(2011). On Literature, the National Literary Prize, and the Rare Consolations of the Writing Life. En Echevarría, I. (Ed.). Between Parenthesis. Essays, Articles, and Speeches, 1998-2003 (pp. 110-113). Nueva York: New Directions.

(2010). Otro cuento ruso. Cuentos. Llamadas telefónicas. Putas asesinas. El gaucho insufrible (pp. 105-108). Barcelona: Anagrama.

(2004). El pasillo sin salida aparente. En Echevarría, I. (Ed.). Entre paréntesis. Ensayos, artículos y discursos (1998-2003) (pp. 7178). Barcelona: Anagrama.

(2003). La pista de hielo. Barcelona: Seix Barral.

(2008). The Romantic Dogs 1980-1998. Nueva York:

New Directions.

(2007). The Savage Detectives. Nueva York: Farrar,

Straus and Grioux. 
(2012). The Secret of Evil. Nueva York: New Directions. (2007). El secreto del mal. Barcelona: Anagrama. (2011). Los sinsabores del verdadero policía. Barcelona:

Anagrama. (2009). The Skating Ring. Nueva York: New Directions. (2004). Sergio González Rodríguez bajo el huracán. En Echevarría, I. (Ed.). Entre paréntesis. Ensayos, artículos y discursos (1998-2003) (pp. 214-216). Barcelona: Anagrama.

(2011). Sergio González Rodríguez in the Eye of the Storm. En Echevarría, I. (Ed.). Between Parenthesis. Essays, Articles, and Speeches, 1998-2003 (pp. 231-232). Nueva York: New Directions.

(2004). Sobre la literatura, el premio nacional de literatura y los raros consuelos del oficio. En Echevarría, I. (Ed.). Entre paréntesis. Ensayos, artículos y discursos (1998-2003) (pp. 102-105). Barcelona: Anagrama.

(2011). The Transparent Mystery of José Donoso. En Echevarría, I. (Ed.). Between Parenthesis. Essays, Articles, and Speeches, 1998-2003 (pp. 107-109). Nueva York: New Directions.

(2011). Tres. Nueva York: New Directions.

(2010). Últimos atardeceres en la tierra. Cuentos. Llamadas telefónicas. Putas asesinas. El gaucho insufrible (pp. 239-264). Barcelona. Anagrama.

Straus and Giroux.

(2012). Woes of the True Policeman. Nueva York: Farrar,

Borges, J. L. (1996). Ficciones. Madrid: Alianza Editorial.

Braithwaite, A. (Ed.) (2008). Bolaño por sí mismo. Entrevistas escogidas. Santiago de Chile: Universidad Diego Portales.

Capital Online (9 de diciembre de 2009). Roberto Bolaño. Cómo se forjó el mito. Recuperado de http://www.capital.cl/cultura/2015/07/15/150747roberto-bolano-como-se-forjo-el-mito-3

Corral, W. H. (2011). Bolaño traducido: nueva literatura mundial. Madrid: Escalera.

Délano, P. (1990). Casi los ingleses de América. Santiago de Chile: Antártica. (1986). En este lugar sagrado. Santiago de Chile: Gali-

nost.

Echevarría, I. (otoño, 2013). Bolaño internacional: algunas reflexiones en torno al éxito internacional de Roberto Bolaño. Estudios públicos, 130, pp. 175-202. 
(21 de enero de 2011). Bolaño. Penúltimos sinsabores de un novelista convertido en leyenda. Recuperado de http://www.elcultural.com/revista/letras/Bolano-Penultimos-sinsabores-de-un-novelistaconvertido-en-leyenda/28519

Franco, J. (2009). Questions for Bolaño. Journal of Latin American Cultural Studies: Travesía, 18 (2-3), pp. 207-217.

Franz, C. (2008). Una tristeza insoportable. Ocho hipótesis sobre la melacholé de B. En Paz, E. y Faverón, G. (Eds.). Bolaño salvaje. Barcelona: Candaya.

López-Calvo, I. (2001). Written in Exile: Chilean Fiction from 1973-Present. Londres y Nueva York: Routledge.

Sanchís, I. (2008). Si hubiera otra vida y fuera posible elegir, escogería ser mujer. En Braithwaite, A. (Ed.). Bolaño por sí mismo. Entrevistas escogidas (pp. 79-81). Santiago de Chile: Universidad Diego Portales.

Swinburn, D. (2008). La novela y el cuento son dos hermanos siameses. En Braithwaite, A. (Ed.). Bolaño por sí mismo. Entrevistas escogidas (pp. 73-78). Santiago de Chile: Universidad Diego Portales. 